\title{
THE MOTIVES OF AMBASSADORS IN BIDDING FOR INTERNATIONAL ASSOCIATION MEETINGS AND EVENTS
}

\author{
LEONIE LOCKSTONE-BINNEY,* PAUL WHITELAW,* MARTIN ROBERTSON,* \\ OLGA JUNEK,* AND IAN MICHAEL†
}

\author{
*College of Business, Victoria University, Melbourne, Victoria, Australia \\ †College of Business, Zayed University, Dubai, UAE
}

\begin{abstract}
As destinations contest the rights to host international association-based meetings and events, competitive points of difference in the bidding process can mean the success or loss of a bid. One of these points of difference has been the growth of ambassador programs worldwide. These programs consist of influential, high-profile individuals, representing their particular industry body or association. Ambassadors work together with destination marketing organizations (DMOs) and meetings/ conference professionals in putting forward bids to their association for future events. To understand the motivations of ambassadors in bidding for international meetings and events, an exploratory study employing an online survey was conducted with ambassadors from three programs, one based in Australia, one based in Southeast Asia, and one in the Middle East. The results provide a demographic profile of ambassadors and highlight their motives for actively bidding for international meetings and events. The study adds to knowledge on a topic for which limited research has been undertaken - that of the bidding process for business events - and expands understanding of how ambassador programs, together with DMOs, can contribute to a professional bidding process for globally roaming international association meetings and events.
\end{abstract}

Key words: Ambassador programs; Bidding; Business events; Destination marketing organizations (DMOs)

\section{Introduction}

Destinations around the world increasingly compete to host globally roaming association meetings and conferences in recognition of the benefits these high-yield events afford. The International Congress and Convention Association (ICCA) estimates 21,000 association meetings and events are held worldwide on a recurring basis by governments and associations, with approximately US $\$ 13$ billion of expenditure generated by this sector in 2011 (ICCA, 2012a). More generally, business events can bring a raft of tourism-related benefits to regions including enhanced destination image and 
minimization of seasonality impacts (Haven-Tang, Jones, \& Webb, 2007). In their report on business events, Jago and Deery (2010) call for quantification of their "beyond tourism benefits" (p. 3), which they purport to include knowledge generation and dissemination and performance enhancement.

In response to the competitive pressures associated with bidding for international association meetings, ambassador programs have sprung up around the world to proactively manage the input of local leaders into the bidding process. ICCA, the membership body representing suppliers [e.g., destination marketing organizations (DMOs), venues, etc.] of the international meetings market, suggest that this innovation has occurred over the last decade with the aim of professionalizing the bidding process at the local level, ensuring destinations are best placed to take advantage of bidding opportunities with ambassadors acting as an "earlywarning system” for requests to bid (ICCA, 2012b, p. 6). Normally hosted by a DMO (e.g., a convention bureau), ambassador programs serve to enable the host "to work with those individuals who are willing, and in a position, to influence, directly or indirectly, the conference destination decisions of the professional institutions to which they belong" (Davidson \& Rogers, 2006, p. 143). In putting forward bids as either individuals as part of a formal bidding group, or representing a formal chapter of an association (ICCA, 2012b), ambassadors act as a conduit through which destinations can systematically identify and attract international meetings and events, distinct from ad hoc, reactive approaches to event bidding.

In a how-to guide for members on setting up ambassador programs, ICCA highlights the following list of potential backgrounds that might make for suitable ambassadors, depending on the types of international meetings and events that a destination is attempting to target: business leaders, senior medical practitioners, scientists, academic leaders, political and social leaders/commentators, and celebrities (ICCA, 2012b). Furthermore the importance of ambassadors having strong links to the destination they are representing, whether it is their place of birth, current place of residence or study, is also highlighted. These high-profile individuals can drive bids through their associations or be the face of the bid representing the destination as a whole (e.g., in the case of celebrities). Apart from bidding, there is a social element to ambassador programs. Davidson and Rogers (2006) note the importance of program hosts keeping their ambassadors motivated and informed with one means of doing so being "regular Ambassador Dinners, which act as recruiting and networking events, providing opportunities for Ambassadors to meet each other, exchange innovative ideas for attracting conferences to the destination and congratulate successful members of the programme" (p. 144).

Numbers of ambassadors per program vary, with some programs intensively managing 20 ambassadors up to programs within excess of 1,000 members (ICCA, 2012b). Glasgow is a prominent example of a large-scale program with over 2,000 members, 1,200 of which are active bidders (Glasgow City Marketing Board, 2012; ICCA, 2012b). There are no reliable figures on the number of ambassador programs worldwide, although anecdotal evidence suggests an increase in uptake as destinations favorably view the competitive advantages associated with these programs, relative to established models such as Club Melbourne (established 2005, cited in Davidson \& Rogers, 2006). Ambassador programs are increasingly seen as a "must-have" in a DMOs' arsenal of strategies for attracting international meetings and events.

Having explained their background and purpose, this article turns to examine the limited literature relating to ambassador programs specifically and event bidding more generally. This review is conducted to underpin the aim of the current study, namely to examine the motives associated with ambassadors becoming active bidders for international association meetings and events.

\section{Literature Review}

The relatively recent emergence of ambassador programs as a destination marketing phenomenon most likely explains the lack of recognition and study of these programs in the extant business events literature. Recent studies assessing progress in the field (Lee \& Back, 2005; Mair, 2012; Yoo \& Weber, 2005) have failed to highlight ambassador programs as a fertile topic for future research. In the most recent review, Mair (2012) notes the continued focus of studies on service satisfaction and site 
selection processes of meeting planners and associations, themes also emphasized in earlier reviews (Lee \& Back, 2005; Yoo \& Weber, 2005). Only one mention of ambassador programs in the academic literature was located. Haven-Tang et al. (2007) highlight ambassador programs as one of seven critical factors associated with successful business tourism destinations, noting, "the use of ambassadors can be crucial in securing business tourism for a destination” (p. 116). The authors go on to stress that these programs need to be well funded and that "when associations invite bids from potential destinations, the local association contact is crucial to the bid process” (Haven-Tang et al., 2007, p. 119).

The next most closely aligned study to the current research is that of Getz's (2004) examination of the bidding processes of Canadian convention and visitor bureaus. In highlighting bidding success as becoming more central to the competitiveness of destinations, Getz (2004) laments that most research attention has been paid to "factors influencing decisions to locate meetings and conventions in a venue or destination" (p. 2) and that "little has been published about the reverse process; namely, how destinations select events and make bids" (p. 3). While Getz's study does not specifically reference ambassador programs, its finding that "strong partners" involved in the bidding process was the top-ranked critical success factor for winning bids by the convention and visitor bureaus studied is indicative of the role ambassadors play in representing their associations and working with DMOs as the "gatekeeper" link to the local partners needed to secure international meetings and events. Indeed, in the emergent model of the event bidding process that Getz proposes at the conclusion of his study, ambassador programs could be positioned as a stand-alone antecedent resource required of DMOs to effectively participate in the bidding process, together with resources and goals of the destination, bid-related services, and marketing. The concept of ambassadors may also be subsumed under Getz's (2004) heading of "relationship building” (p. 20) in recognition of the role an ambassador program plays as a relationship management tool (ICCA, 2012b).

Getz's (2004) study of event bidding focused on both business and leisure events. No other studies on the bidding process for business events could be found and likewise no additional works examining the bidding process from the perspective of DMOs could be located, confirming that research has not advanced significantly since Getz's study. However, there has been more research attention paid to the bidding process for major sporting events (Emery, 2002; Ingerson \& Westerbeek, 2000; Westerbeek, Turner, \& Ingerson, 2002). In its own right, this topic also has a limited research base to support it.

Building on Ingerson and Westerbeek's (2000) earlier qualitative work, Westerbeek et al. (2002) factor analyzed 69 importance statements resulting in eight exploratory success factors (representing 51 items) underlying the major sporting event bid process. These factors were rated in order of importance as 1) ability to organize events, 2) political support, 3) infrastructure, 4) existing facilities, 5) communication and exposure, 6) accountability, 7) bid team composition and 8) relationship marketing by 135 respondents from 21 different countries, representing event owners and organizers with experience of the bidding process associated with major sporting events. The authors labeled factors 1 to 4 as "vital" to the bidding process and the latter four as "supporting" factors, pertaining to which, "distinct competitive differences between event-bidding organizations can emerge. For example, the unique (and intangible) composition of the bid team will have a great impact on establishing (intangible networks) with power brokers, relations with media, and the reputation of the bidding organization" (Westerbeek et al., 2002, p. 320). The authors go onto note that most bidding organizations will compete on par with each other in terms of vital tangible factors so that supporting factors may in fact be the point of difference between successful and unsuccessful bids. We argue that ambassador programs can similarly be considered as a supporting factor that can provide an advantage for destinations over competitor offers in the business events market.

Having reviewed the limited literature relating to ambassador programs specifically and event bidding more generally, it is worthwhile to briefly consider the practitioner material on ambassador programs highlighted in the introduction to this study. The ICCA (2012b) publication details the potential return on investment to destinations from hosting an ambassador program and provides an overview of some of the strategic considerations that DMOs should consider when setting up such a program. 
These considerations include a long-term commitment to the established program, given the long lead times involved in bidding for and, if successful, running association events and ensuring alignment of the program's objectives to those of key local stakeholders (e.g., universities). Likewise, Davidson and Rogers's (2006) text details the key points to setting up an ambassador program. These publications focus on program design and operation rather than the individuals directly involved in these programs, the ambassadors themselves. To the knowledge of the authors, the current study is the first of its kind to examine the inner workings of ambassador programs from the personal perspective of those involved.

\section{Methodology}

A quantitative method was adopted to address the research aim of examining the motives associated with ambassadors becoming active bidders for international association meetings and events. This approach is akin to Getz's (2004) quantitative study for which he noted "this research is exploratory in that little pertinent research had been reported in the literature, and theoretical guidance was minimal" (p. 9). Likewise, the current study should be considered exploratory, given the lack of previous research on the role of ambassadors in bidding for events.

ICCA provided Victoria University (a university member of the organization) seed funding to conduct the study at hand, with a view to disseminating the findings in this underresearched area to its members at its annual Congress and as input into future revisions of its how-to guide (ICCA, 2012b). ICCA further supported the research by facilitating access to two ambassador programs, one located in Australia and one located in Southeast Asia. An additional program, located in the Middle East, also agreed to participate in the study. The three programs sampled offered a mix of new and well-established (from mid-2000) models, two of which can be classed as midsize programs (100150 members), with the remaining program containing a small cohort of 20 ambassadors. In total, 288 ambassadors across the three programs were approached to participate in the study.

Cost, time, and distance constraints dictated the use of an online survey. An invitation to participate in the study was sent via email from the ambassador program organizers, which in the instance of the Southeast Asian and Middle Eastern programs were the convention bureaus representing each destination. In the case of the Australian program, the invitation was forwarded by a major venue, which hosts the program, working closely with the local convention bureau to do so. The email contained a brief introduction to the study and participants were asked to read an accompanying information sheet, which provided a detailed, plain English explanation of the project, an overview of potential risks of participating, and details of the researchers conducting the study. The granting of informed consent by the respondents was assumed from them having read these details and then clicking on the embedded link contained in the email to complete the survey. Victoria University's Human Research Ethics Committee formally approved this research approach.

The key components of the survey instrument covered demographic information (e.g., gender, age, education, current employment profile, association linkages, etc.), motivations for bidding, and the outcomes of recent bidding activities. As noted, there was little in the way of previous academic or practitioner work to help guide this study and specifically the design of the questionnaire. Given their centrality to the current study, the motivation items were developed with input from representatives at ICCA's Head Office in The Netherlands and piloted with the program organizers that were facilitating access to the ambassador sample. The final version of the questionnaire was administered late September-early October 2012, with reminders sent via the program organizers during this period in order to boost the response rate. The online survey was administered in English and hosted on a secure, commercial online survey service known as QSmart. At the close of the survey period, 56 responses had been received from across the three programs for an overall response rate of $19.4 \%$. This response rate is acceptable given the select group of people surveyed and the acknowledged issue of lower response rates associated with online survey administration (Manfreda, Bosnjak, Berzelak, Haas, \&Vehovar, 2008). This study therefore provides indicative insights into the research topic, which a more robust examination can later seek to confirm. 
The data were analyzed using IBM Statistics (SPSS) v. 20. Akin to Getz's (2004) exploratory study, descriptive analysis was used for data screening purposes as well as providing a snapshot of the ambassadors, their motives, and their bidding activities. The data yielded the potential for crosscase comparisons of the ambassadors in the various programs surveyed. The decision was made based on the relatively small numbers per program not to proceed with such analysis in order to protect the identity of the participants and the commercial interests of the program organizers that had granted access to their ambassadors for sampling purposes.

The findings of this exploratory study of the motives of ambassadors in bidding for globally roaming association meetings and events are detailed in the following section.

\section{Results and Discussion}

To frame the findings presented, a demographic profile of the ambassadors surveyed is firstly presented, which in turn is accompanied by a profile of their recent conference attendance and bidding activity.

The findings indicated that in the majority the returned sample was male (64\%), with a postgraduate qualification (89\%) and employed on a fulltime basis (79\%). The age of the respondents was fairly evenly spread across the middle age ranges, with $23 \%$ of respondents aged 30-39 years old, a further $21 \%$ aged $40-49$ years, and the most common grouping of ambassadors (36\%) aged 50-59 years. Common occupations of the ambassadors surveyed included director (19.6\%), professor (14.3\%), doctor (12.5\%), manager (10.7\%), and associate professor (8.9\%). This combined picture is indicative of the ambassadors surveyed being mature aged, highly educated, and holding senior positions, aligned to those groups that the practitioner literature (ICCA, 2012b) suggests should be targeted when recruiting ambassadors.

The importance of ambassadors and their links to professional associations and other networks cannot be underestimated. Separately assessed, 57\% of respondents were members of a nationally based professional association and 70\% were associated with an equivalent international association. As previously highlighted, as the local links to professional associations, the knowledge, networks, and insights of ambassadors are critical to the bidding process (Haven-Tang et al., 2007) for the roaming events these associations own and award the rights to destinations to run. The returned sample of ambassadors also showed a preponderance of membership of other networks. Forty-eight percent sat on a government committee or advisory body, $12.5 \%$ were members of a sporting club, and $10.7 \%$ were members of a trade association (either nationally or internationally based). In addition, they were inclined to be active members of these networks, holding executive roles associated with their various memberships. Separately assessed, $29 \%$ of the ambassadors surveyed held a chairing role, $11 \%$ that of secretary, $4 \%$ treasurer, with a further $39 \%$ holding general board or committee membership or a subcommittee role.

Table 1 provides an overview of the ambassadors' activity relating to their program membership and record of attending international meetings and events.

The findings highlight that the majority of ambassadors were relatively new to their programs, with only $29 \%$ of respondents being appointed as members for 4 years or more. This outcome is most likely indicative of the relative newness of two of the three programs sampled, with the Southeast Asian program operating since 2009 and Middle Eastern counterpart launched even more recently in 2011. The Australian program, in operation since 2005, accounts for the majority of longer term ambassadors, although separate analysis of the responses of this cohort indicates that $50 \%$ of the members had tenure for less than 3 years. The practitioner literature suggests that a process of renewal should be actively undertaken by program managers to recruit new members and retire those whose bidding activity may have ceased (ICCA, 2012b). It would appear that there is preliminary evidence of this occurring in relation to the Australian program.

Relevant to the point regarding nonactive ambassadors, the results in Table 1 suggest that in 2011, just over one third of ambassadors did not attend any official program functions or events, therefore failing to engage with their program and fellow ambassadors. While acknowledging there may have been good grounds for this finding (e.g., work and other commitments impinging on availability), given the importance placed on such events in the literature 
Table 1

Ambassador Activity Profile

\begin{tabular}{|c|c|c|}
\hline & $N$ & Valid Percentage \\
\hline \multicolumn{3}{|c|}{ Duration of program membership } \\
\hline Less than 2 years & 28 & 50.0 \\
\hline $2-3$ years & 12 & 21.4 \\
\hline 4-5 years & 10 & 17.9 \\
\hline $6-8$ years & 3 & 5.4 \\
\hline $8+$ years & 3 & 5.4 \\
\hline \multicolumn{3}{|c|}{$\begin{array}{l}\text { Number of ambassador program } \\
\text { events/functions attended in } 2011\end{array}$} \\
\hline None & 20 & 35.7 \\
\hline 1 & 16 & 28.6 \\
\hline $2-3$ & 14 & 25.0 \\
\hline $4-5$ & 4 & 7.1 \\
\hline $6+$ & 2 & 3.6 \\
\hline \multicolumn{3}{|c|}{$\begin{array}{l}\text { Number of international meetings/ } \\
\text { events attended in the past } 2 \text { years }\end{array}$} \\
\hline None & 1 & 1.8 \\
\hline $1-2$ & 16 & 28.6 \\
\hline $3-4$ & 20 & 35.7 \\
\hline $5-6$ & 2 & 3.6 \\
\hline $7+$ & 17 & 30.4 \\
\hline \multicolumn{3}{|c|}{$\begin{array}{l}\text { As an ambassador, number of } \\
\text { international meetings/events } \\
\text { bid for in the past } 2 \text { years }\end{array}$} \\
\hline None & 19 & 33.9 \\
\hline $1-2$ & 28 & 50.0 \\
\hline $3-4$ & 7 & 12.5 \\
\hline $5-6$ & 1 & 1.8 \\
\hline $7+$ & 1 & 1.8 \\
\hline \multicolumn{3}{|c|}{ Outcome of the most recent bid } \\
\hline Successful & 28 & 75.7 \\
\hline Unsuccessful & 9 & 24.3 \\
\hline
\end{tabular}

(Davidson \& Rogers, 2006; ICCA, 2012b) as a means of motivating ambassadors, keeping them informed of program aims and allowing them to network with their fellow members, it is perhaps of concern that some ambassadors appear to be missing out on these benefits. In contrast, the respondents were more regular attendees of international meetings and events, which for the purposes of this study were defined in the questionnaire introduction as: congresses, conferences, meetings, and all other business events that are regularly occurring, roaming in location (hosted in a new location each time) and competitively bid for. Ninety-eight percent of the returned sample had attended at least one international meeting or event during the previous 2 years, with $30 \%$ reporting having attended seven or more such events.

Given that the purported role of ambassador programs is to enable DMOs to bid for international association meetings and events using the expertise and networks of local leaders, it is pleasing to see that the results by and large confirm this to be the case. Approximately two thirds of the ambassadors surveyed had been involved in a bid to host an international event in the previous 2 years. Of those bids, $76 \%$ had proven successful with ambassador input. As ICCA notes in its ambassador program guide, "destinations and venues which work closely with Ambassadors are usually more successful in their bids, since their approach can consistently combine professional support with internal knowledge of association-specific objectives” (ICCA, 2012b, p. 6). These results lend support to what has been to now largely anecdotal evidence for the value of ambassador programs in facilitating bidding success.

To address the overriding research aim of examining the motives associated with ambassadors becoming active bidders for international association meetings and events, the responses of those ambassadors who had participated in a bid in the previous 2 years were analyzed. Motive items were assessed using a 7-point scale labeled from $1=$ not at all important to 7 = extremely important. Descriptive analysis of these items is presented in Table 2, with motives ranked according to importance (highest through to lowest).

As previously noted, the current study is the first of its kind to examine the inner workings of ambassador programs from the personal perspective of those involved. As such the authors had no previous frame of reference that might give some a priori indication of the likely motives of ambassadors for bidding, except for the insights afforded from preliminary discussions with staff from ICCA's Head Office. These discussions led the researchers to suppose that some of the more personal benefits assessed might feature more prominently in the ranking of motives than was actually revealed to be the case. Indeed, the highest ranked personal benefit, increased personal or professional profile, weighs in at number five in terms of importance, with social or other benefits afforded the least importance of the motives assessed. Perhaps it is not surprising that another personal benefit, the item assessing "career benefits" rates relatively lowly (rank 11). As the demographic data indicated, many ambassadors were already in senior roles. For most part, their recognized reputation and networks in a 
Table 2

Ambassador Motives for Bidding

\begin{tabular}{|c|c|c|}
\hline Rank/Motive & $\begin{array}{l}\text { Mean } \\
(n=31)\end{array}$ & SD \\
\hline $\begin{array}{l}\text { 1. Prestige or recognition for your } \\
\text { professional body }\end{array}$ & 5.58 & 1.88 \\
\hline 2. Professional body support & 5.52 & 1.69 \\
\hline $\begin{array}{l}\text { 3. Prestige or recognition for your } \\
\text { country, region or city }\end{array}$ & 5.45 & 1.79 \\
\hline $\begin{array}{l}\text { 4. Economic benefits for your country, } \\
\text { region, city or professional body }\end{array}$ & 5.06 & 1.90 \\
\hline $\begin{array}{l}\text { 5. Increased personal or professional } \\
\text { profile }\end{array}$ & 4.81 & 1.99 \\
\hline 6. Government directive/support & 4.55 & 2.03 \\
\hline $\begin{array}{l}\text { 7. A prior indication of a high probability } \\
\text { of success by the award body }\end{array}$ & 4.52 & 1.67 \\
\hline $\begin{array}{l}\text { 8. Personal encouragement by key } \\
\text { stakeholders }\end{array}$ & 4.48 & 2.13 \\
\hline $\begin{array}{l}\text { 9. Prestige or recognition for your } \\
\text { employer }\end{array}$ & 4.45 & 2.06 \\
\hline 10. Corporate support & 4.26 & 2.03 \\
\hline 11. Career benefits & 4.13 & 2.13 \\
\hline 12. Potential media coverage & 3.97 & 2.21 \\
\hline 13. Social or other benefits & 3.77 & 2.04 \\
\hline
\end{tabular}

particular field would bring about their invitation to become ambassadors in the first instance. As such, the current results appear to indicate that ambassadors already at the top of their fields may downplay the importance attached to bidding for international meetings and events as a means of furthering their careers. Organizers might be better placed in selling their ambassador programs as a mark of distinction for those already firmly established in their fields.

Rather than personal benefits, the motives of ambassadors in bidding for international meetings and events were more strongly associated with the potential prestige, reputation, and economic benefits to be bestowed on their professional association or body as a result of a successful bid, together with these same benefits flowing on to their host destination. These rankings would seem to suggest that in the programs under study, the motives of ambassadors in bidding for events are quite utilitarian. While there may be a raft of activities hosted under the auspices of ambassador programs (e.g., networking events, award presentations, concerts, etc.), these appear to be of secondary value to the importance ambassadors place on serving their destinations as a conduit for attracting international meetings and events. Indeed, the importance of the destination and the association appear to go hand in hand in motivating ambassadors to bid, rather than simply engaging with the ancillary activities of these programs or lapsing to become wholly nonactive members.

To capture the views of all respondents, of whose who had ( $n=37,66 \%)$ and had not $(n=19,39 \%)$ been active bidders to date, the relative importance of a set of items to the bidding process for international meetings and events was assessed using a 7-point scale (labeled from 1 = not at all important to 7 = extremely important).

Table 3 indicates that all but one item assessed rated above the scale midpoint in terms of importance when bidding for international meetings and events. "Risk of not bidding," the lowest ranked item, suggests that the ambassadors surveyed lack awareness of the competitive bidding environment for international association events and the risk or "opportunity lost” if bids are not pursued. Ambassadors may not see this as being their area of concern but rather view it as the DMO's responsibility to assess and manage such risks on behalf of their destination.

Once again the importance of professional networks in facilitating bidding action is highlighted. As conduit between the DMO and their particular association or professional body, an ambassador is

Table 3

Items of Importance Related to Bidding

\begin{tabular}{|c|c|c|c|}
\hline Rank/Item (Measured on 7-Point Scale) & $N$ & Mean & SD \\
\hline 1. Your professional networks & 47 & 5.96 & 1.30 \\
\hline 2. Resources available to make a bid & 46 & 5.80 & 1.39 \\
\hline $\begin{array}{l}\text { 3. Support from the local meetings } \\
\text { industry }\end{array}$ & 47 & 5.79 & 1.43 \\
\hline $\begin{array}{l}\text { 4. Likely reputational benefits in your } \\
\text { field from hosting the event }\end{array}$ & 47 & 5.74 & 1.44 \\
\hline 5. Profile of the event & 46 & 5.70 & 1.38 \\
\hline 6. Likelihood of bid success & 45 & 5.27 & 1.53 \\
\hline 7. Available time & 45 & 5.24 & 1.63 \\
\hline $\begin{array}{l}\text { 8. Likely economic impact of the } \\
\text { event }\end{array}$ & 47 & 5.23 & 1.49 \\
\hline 9. Your personal networks & 46 & 5.17 & 1.69 \\
\hline 10. Cost of bidding & 47 & 4.68 & 1.96 \\
\hline $\begin{array}{l}\text { 11. Your level of influence over the } \\
\text { event if the bid is successful }\end{array}$ & 47 & 4.47 & 1.94 \\
\hline 12. Complexity of bid requirements & 46 & 4.43 & 1.92 \\
\hline $\begin{array}{l}\text { 13. Your role in the event of a success- } \\
\text { ful bid }\end{array}$ & 47 & 4.40 & 1.90 \\
\hline $\begin{array}{l}\text { 14. Risk of not hosting the event } \\
\text { successfully }\end{array}$ & 46 & 3.87 & 2.10 \\
\hline 15. Risk of not bidding & 46 & 2.80 & 1.76 \\
\hline
\end{tabular}


unlikely to champion a bid if support at the local level is not forthcoming. The data also reveal that resources and the support of the local meetings industry are two other requisite precursors to bidding highly valued by ambassadors. DMOs, working on behalf of the meetings industry, may provide ambassadors with one or more of the following forms of bidding support: feasibility studies to establish a business case for bidding, assistance with preparing the bid documentation, venue and accommodation booking assistance, provision of delegate packs and marketing collateral and organization of pre- and posttours (Getz, 2004; ICCA, 2012b).

Having examined particular items that might facilitate ambassadors in championing bids, all respondents were subsequently asked about their future bidding intentions, together with a series of summary statements regarding the value of ambassador programs (assessed on a graphic rating scale of 1 = strongly disagree to $100=$ strongly agree) .

The results in Table 4 indicate a moderate level of agreement with the bidding intention statements. Given $66 \%$ of the respondents had already participated in a bid in the previous 2 years, of which $76 \%$ of bids had proven successful, these indicative statements may suggest that, for some ambassadors surveyed, key international events in their field of expertise had already been bid for quite recently. Subsequent bids might not be planned given their roaming nature means that "many biddable events

Table 4

Bidding Intentions and Summary Statements

\begin{tabular}{llll}
\hline $\begin{array}{l}\text { Reason } \\
\text { (Measured on Scale: 1 to 100) }\end{array}$ & $N$ & Mean & SD \\
\hline $\begin{array}{l}\text { I intend to bid for an international } \\
\text { meeting/event in the next 12 months }\end{array}$ & 53 & 63.17 & 29.35 \\
$\begin{array}{l}\text { Beyond the next 12 months, I intend } \\
\text { to bid for an international meeting/ } \\
\text { event in the next 2-3 years }\end{array}$ & 54 & 70.20 & 21.69 \\
$\begin{array}{l}\text { My membership of an ambassador } \\
\text { program has assisted me in bidding } \\
\text { for international meetings/events }\end{array}$ & 56 & 69.02 & 25.27 \\
$\begin{array}{l}\text { My membership of an ambassador } \\
\text { program has assisted me in }\end{array}$ & 55 & 62.22 & 23.22 \\
$\begin{array}{l}\text { winning bids for international } \\
\text { meetings/events }\end{array}$ & & & \\
$\begin{array}{l}\text { Ambassador programs have an } \\
\text { important role to play in ensuring } \\
\text { destinations attract international } \\
\text { meetings/events }\end{array}$ & 56 & 78.66 & 17.70 \\
\hline
\end{tabular}

are one-time only (or at least they are unlikely to return to a destination frequently)" (Getz, 2004, p. 6). Stronger support is demonstrated for the value of ambassador programs in bidding for and securing international meetings and events. While there may be an inherent level of bias, given it is the ambassadors themselves making this assessment, these results support Haven-Tang et al.'s (2007) earlier finding of the critical role ambassador programs play in driving successful business tourism destinations.

\section{Conclusion}

This article provides preliminary support for the role of ambassador programs in enabling DMOs to bid for international association meetings and events using the expertise and networks of local leaders to do so.

The following observations have been made from the limited available literature. Ambassador programs have been recognized for their capacity to facilitate relationships between stakeholders (Getz, 2004; ICCA, 2012b). There has also been recognition of the broader value of business events as drivers for successful destinations and legacies (Edwards, Foley, \& Schlenker, 2011; Haven-Tang et al., 2007; Jago \& Deery, 2010, 2011). Indeed, ambassador programs may prove a tangible conduit through which to examine some of the intangible benefits of the business events sector that are often talked about but rarely studied.

The inner workings of ambassador programs and the motives of ambassadors have to date been unclear. The results of this study indicate ambassadors were not motivated by personal gain. Rather, the relationship with the wider professional association or body to which the ambassador was linked was far more significant. Specifically, the more tangible benefits of physical rewards (e.g., through social events, dining, or other entertainment) were not strong motives, while reputation and prestige for the professional body and destination the ambassadors were representing came to the fore. What has been a revelation is that in highlighting the importance ascribed to the ambassador program, the respondent analysis indicates that the existence of, and support for, the ambassador program is in itself an intrinsic motivation. 
Success in the future may require more explicit functions for ambassador programs (e.g.,, negotiating and executing more sustainable business practice). Accordingly, beyond identifying that traditional (tangible) rewards are not as highly rated, further investigation of the intrinsic motives of ambassadors in bidding for international meetings and events is required. The authors suggest that this is all the more the case as competition (between associations and destinations) to win major bids increases. A number of broad questions can be posed to gain this understanding. One pertinent question could be: Is a formalized measure of ambassador success likely to motivate better performance as has been examined elsewhere in industry (Wiersa, 1992)? Moreover, what are-and in what form — do psychological interrelations with the organization or network of organizations exist and to what extent do they affect the incentive to perform better (Fehr \& Falk, 2002)? Specifically, how do social approval and perceived social and cultural norms (Festré, 2010; Kolstad, 2007; Sosik\& Dinger, 2007) influence ambassador behavior?

A depth of understanding brought to addressing these questions may have further application to several areas already identified as vital in securing important bids; that is, brokerage of power (political and intraorganizational), integration with media stakeholders (social and traditional news media), and a further integration with other stakeholders in the host destination. Further and clearer understanding of ambassador motives (and intrinsic rewards) may facilitate these developments.

The authors acknowledge the limitations of the current study in quantitatively examining a small cross-sectional sample of ambassadors. Indeed, our research continues what Mair (2012) notes is a tradition in the business events literature-namely, an overreliance on quantitative data, the analysis of which remains largely descriptive. We concede this limitation and agree that qualitative interrogation of ambassador motives for bidding would add depth and richness that the current data lacks. However, we argue that, akin to Getz's (2004) exploratory study of event bidding that only presented descriptive analysis, given this is the first study to examine ambassador programs in a concerted manner, with responses from a very high-profile group, who, it could be reasonably assumed, are time poor, the study makes a worthwhile contribution. We envision that academics and practitioners alike will increasingly view the ambassador program phenomenon as a fertile area of research, one of which professionalizes event bidding for all stakeholders involved.

\section{Acknowledgment}

The authors wish to thank ICAA for its support of this study.

\section{References}

Davidson, R., \& Rogers, T. (2006). Marketing destinations and venues for conferences, conventions and business events: A convention and event perspective. Burlington, MA: Butterworth-Heinemann.

Edwards, D., Foley, C., \& Schlenker, K. (2011). Beyond tourism benefits: Measuring the social legacies of business events. Sydney: University of Technology Sydney.

Emery, P. R. (2002). Bidding to host a major sports event: The local organising committee perspective. International Journal of Public Sector Management, 15(4), 316-335.

Fehr, E., \& Falk, A. (2002). Psychological foundations of incentives. European Economic Review, 46(4-5), 687-724.

Festré, A. (2010). Incentives and social norms: A motivationbased economic analysis of social norms. Journal of Economic Surveys, 24(3), 511-538.

Getz, D. (2004). Bidding on events: Identifying event selection criteria and critical success factors. Journal of Convention \& Exhibition Management, 5(2), 1-24.

Glasgow City Marketing Board. (2012). Glasgow conference ambassador programme FAQ. Retrieved from http://conventions.seeglasgow.com/glasgow-conferenceambassador-programme/faq/

Haven-Tang, C., Jones, E., \& Webb, C. (2007). Critical success factors for business tourism destinations: Exploiting Cardiff's national capital city status and shaping its business tourism offer. Journal of Travel \& Tourism Marketing, 22(3/4), 109-120.

Ingerson, L., \& Westerbeek, H. (2000). Determining key success criteria for attracting hallmark sporting events. Pacific Tourism Review, 3(4), 239-253.

International Congress and Convention Association. (2012a). Statistics report 2002-2011: International association meetings market. Amsterdam, Netherlands: Author.

International Congress and Convention Association. (2012b). Congress ambassador programmes. Amsterdam, Netherlands: Author.

Jago, L., \& Deery, M. (2010). Delivering innovation, knowledge and performance: The role of business events. Melbourne: Business Events Council of Australia.

Jago, L., \& Deery, M. (2011). The holistic value of events: Interim report. Melbourne: Melbourne Convention and Visitors Bureau. 
Kolstad, I. (2007). The evolution of social norms: With managerial implications. Journal of Socio-Economics, 36(1), 58-72.

Lee, J. L., \& Back, K-J. (2005). A review of convention and meeting management research 1990-2003: Identification of statistical methods and subject areas. Journal of Convention \& Event Tourism, 7(2), 1-20.

Mair, J. (2012). A review of business events literature. Event Management, 16, 133-141.

Manfreda, K. L., Bosnjak, M., Berzelak, J., Haas, I., \& Vehovar, V. (2008). Web surveys versus other survey modes: A meta-analysis comparing response rates. International Journal of Market Research, 50(1), 79-104.
Sosik, J. J., \& Dinger, S. L. (2007). Relationships between leadership style and vision content: The moderating role of need for social approval, self-monitoring, and need for social power. The Leadership Quarterly, 18(2), 134-153.

Wiersma, U. J. (1992). The effects of extrinsic rewards in intrinsic motivation: A meta-analysis. Journal of Occupational \& Organizational Psychology, 65(2), 101-114.

Westerbeek, H., Turner, P., \& Ingerson, L. (2002). Key success factors in bidding for hallmark sporting events. International Marketing Review, 19(3), 303-322.

Yoo, J. J-E., Weber, K. (2005). Progress in convention tourism research. Journal of Hospitality \& Tourism Research, 29(2), 194-222. 